\title{
EREBEA
}

Revista de Humanidades

y Ciencias Sociales

NúM. 4 (2014), pp. 145-170

ISSN: 0214-0691

\section{El PROCESO DE REDUCCión DE hospitales EN LA ANDALUCÍA Rural. Los hospitales de Niebla y La Palma (I 590-i 847). CONFLICTOS, CORRUPTELAS Y DESOBEDIENCIAS}

Francisco Núñez Roldán

Universidad de Sevilla

RESUMEN

El artículo analiza cómo el proceso de reducción de hospitales auspiciado por Felipe II afectó a estas instituciones de socorro rural, concretamente a los hospitales de Niebla y La Palma. En ésta, los tres centros que sobrevivieron al proceso, oponiéndose al mismo, incrementaron su labor asistencial y educativa hasta mediados del siglo XIX. En Niebla, en cambio, donde los hospitales no pudieron resistir la política de reducción, se desarrolló, gracias a la misma, una efectiva hospitalidad.
Palabras Clave

Pobreza, Hospitalidad Rural, Asistencia Social, La Palma, Niebla
Abstract

The article discusses how the process of reducing hospitals sponsored by Philip II afected these institutions of rural relief, namely the Niebla and La Palma hospitals. In it, the three centers that survived the process, opposing the same, increased their welfare and educational work until the mid nineteenth century. In Niebla, however, where hospitals could not resist the reduction policy, an effective hospitality was developed, thanks to it.
KeYwords

Poverty, Rural Hospitality, Social Care, La Palma, Niebla 

Si tuviésemos que definir en unas palabras la realidad social europea del siglo XVI destacaríamos, por encima de todo, la universalidad de la pobreza: en todos los países que hoy componen el viejo continente, en el norte y en el sur, en el este y en el oeste, en monarquías y en principados, en las ciudades y en el mundo rural. Esa es la razón por la cual la historiografía, que se ha ocupado de ella desde hace algunas décadas, ha producido cientos de títulos imposibles de traer aquí ${ }^{1}$. Ya entonces, en el propio siglo XVI, las instituciones políticas, monarquías y ciudades, intentaron infructuosamente atajar lo que consideraban un problema y una amenaza social, ofreciendo como socorro inmediato la red de hospitales de origen medieval. Al mismo tiempo, algunos humanistas, al servicio o no de esas instituciones, debatieron las raices del mal, analizaron racionalmente la cuestión y propusieron soluciones de índoles diversas, a veces opuestas. Y también la literatura se hizo eco del drama eligiendo modelos reales que ilustraban, bajo distintos prismas e intenciones morales, una realidad social sofocante.

Los territorios de la monarquía hispánica no fueron ajenos al drama de la pobreza. Es conocido de sobra el debate que tuvo lugar sobre qué hacer con los pobres entre Domingo de Soto y Juan de Robles o los tratados de J.L. Vives y Cristóbal Pérez de Herrera que proponían cómo remediarla. No es este el lugar para hacer una síntesis acerca de la cuestión ni es nuestro propósito. No obstante, desde el punto de vista del socorro y del recogimiento cotidiano de los pobres, de la mendicidad, de la orfandad, de la miseria, del hambre, los hospitales y las instituciones de caridad jugaron un papel decisivo en su alivio. En este sentido, durante los siglos XIV y XV se produjo en España un incremento de la hospitalidad pública y de las cofradías de caridad de tal dimensión que, recién iniciado el siglo $\mathrm{XVI}$, se reclamaba una reforma moderna de un sistema asistencial que presentaba muchas deficiencias. No obstante, en opinión de J.I. Carmona, la proliferación de pequeños establecimientos se mantuvo durante el siglo XVI, de manera que una

1 No obstante la prolífica labor de los historiadores, solo podemos citar algunas de las obras más influyentes desde que comenzara a estudiarse el fenómeno de la pobreza en los años 60. De traer algunos títulos, es ineludible recordar a Michel Mollat, Les pauvres au Moyen Age, Hachette, Paris, 1978; Bronislaw Geremek, La estirpe de Cain, Mondadori, Madrid, 1991.La edición y la introducción de Michel Cavillac al Amparo de pobres de Cristóbal Perez de Herrera, Espasa Calpe, Madrid, 1975. 
localidad por pequeña que fuese contaba con su hospital ${ }^{2}$. La historiografía se ha ocupado de los hospitales urbanos y ha prestado muy poca atención a la asistencia social en el mundo rural. Este artículo pretende estudiar cómo el proceso de reducción de hospitales llevado a cabo por Felipe II intentó mejorar la asistencia social, cómo afectó a ciertas instituciones rurales andaluzas y qué consecuencias se derivaron de su aplicación.

A mediados del siglo XVIII el reino de Sevilla sumaba algo más de un centenar de hospitales para curación de hombres y mujeres enfermas, de los cuales, cuarenta, es decir, algo más de un tercio, se encontraban en la actual provincia de Huelva ${ }^{3}$. $\mathrm{Si}$ a esa cifra se le suman las nueve casas de hospedaje repartidas en diferentes pueblos, el porcentaje aumenta. El número de hospitales con respecto al siglo XVI no pareció disminuir drásticamente y los problemas que les aquejaban tampoco.

En el siglo XVIII la mayor parte de los hospitales onubenses se hallaban en los municipios del sur a lo largo del litoral y de la campiña, siguiendo el eje marcado por el camino real que llevaba desde Sevilla a Ayamonte. A uno y otro lado de la ruta, no había pueblo que no tuviera su hospital y algunos como Huelva, Beas, Trigueros, La Palma, Villalba del Alcor, Paterna y Ayamonte, más de uno. En la Sierra los hospitales se dispersaban por los grandes municipios, Aracena, Cortegana, Aroche, Almonaster, Encinasola y como ocurría en el sur, en el camino que unía Sevilla con Extremadura, de manera que había hospitales en Zufre, Santa Olalla y Cala. En el Andévalo, en cambio, no se fundaron hospitales propiamente dichos, sino casas que no disponían de hospitalidad y que se limitaban a dar asilo a pobres transeúntes.

Ya he apuntado en otro lugar la labor hospitalaria y caritativa llevada a cabo por estas instituciones en el siglo XVIII y su administración ${ }^{4}$. La mayor parte de ellas tenían como tarea específica la curación de pobres enfermos y solo unos pocos se ocupaban del tránsito y el alojamiento eventual de nińos expósitos. Y por lo que respecta a la gestión económica de los hospitales, la mayoría de ellos se financiaban con rentas procedentes de inmuebles, de censos, de arrendamientos de pequeñas propiedades agrícolas y en casos excepcionales de limosnas. Casi todos tenían ingresos muy cortos, incapaces de satisfacer la demanda caritativa y hospitalaria, pero gracias a la reducción de hospitales llevada a cabo a finales del siglo XVI, algunos se convirtieron, al llegar al siglo XVIII, en grandes hacendados en sus pueblos, como es el caso del hospital de Nuestra Señora de los Ángeles de

2 Aunque apenas se dedican unas líneas a la hospitalidad en el mundo rural, para un conocimiento detallado del proceso de reducción hospitalaria llevado a cabo en la ciudad de Sevilla a finales del siglo XVI véase J.I. Carmona García, El sistema de hospitalidad pública en la Sevilla del Antiguo Régimen, Sevilla, Diputación Provincial, 1980, p. 25

$3 \mathrm{Al}$ respecto véase F. Nuñez Roldan, "Enfermedades, hospitalidad y terapéutica en las comarcas onubenses a fines del Antiguo Régimen” en Huelva en su Historia,2, 1988, pp.451-490

4 Ibidem pp. 484-489 
Niebla $^{5}$. Sus ingresos anuales se calculaban en 63.437 reales según el Libro del Mayor Hacendado del Catastro de Ensenada, y era propietario de 1.006 aranzadas de tierra, la mayoría de ellas de sembradura de secano y, asimismo, poseía la mitad de un molino harinero, unas casas y dos portales para feria y varios tributos a su favor, de manera que su capital era uno de los más gruesos entre los mayores hacendados del occidente del reino de Sevilla a mediados del siglo XVIII.

Y lo era, en realidad, porque este hospital de la capital del condado que llevaba su nombre, fue el resultado del proceso de reducción y de concentración de hospitales llevado a cabo por la Monarquía de acuerdo con la Iglesia a lo largo del siglo XVI y que culminaría en la última década del siglo, según Carmona, con resultados desiguales $^{6}$. El fin de las reducciones en los distintos lugares en los que se intentó aplicar consistía en disminuir el número de hospitales sobre la base de concentrarlos en uno solo o a lo sumo en unos pocos si se trataba de una gran ciudad como Sevilla. Se conseguiría administrar mejor sus rentas uniendo las haciendas de los reducidos en uno solo y se atendería mejor la hospitalidad para la que fueron fundados.

Conocemos muy bien el procedimiento para llevar a efecto las reducciones en el arzobispado de Sevilla y no es necesario una descripción detallada del mismo. Sin embargo, sabemos muy poco del mismo proceso en el medio rural o en otras villas y ciudades de su reino, de manera que este trabajo representa una primicia dentro de una investigación más amplia que tiene como objetivo el desarrollo y la evolución de la hospitalidad rural en el antiguo reino hispalense. Me limitaré, no obstante, al análisis de las reducciones llevadas a cabo entre 1590 y 1593 en algunas poblaciones del sur de la actual provincia de Huelva y me detendré especialmente en las que se produjeron en Niebla y La Palma, la primera satisfactoria, la segunda fracasada, cómo se iniciaron, qué información se obtuvo de la averiguación llevada a cabo en ellas por el visitador arzobispal, cuál era la situación financiera en ese momento de los hospitales, cuáles sus deficiencias asistenciales, qué resistencias se produjeron al proceso y, por último, de qué manera se administraron algunos de los hospitales ${ }^{7}$.

El visitador enviado por el provisor arzobispal para hacer las diligencias previas a la reforma del sistema hospitalario en los lugares que se hallaban a lo largo del camino que unía Sevilla con Ayamonte fue el doctor Pedro de Frías que visitó los hospitales durante la primavera y los comienzos del verano del año 1590 . Y en Niebla se ocupó de la tarea el presbítero beneficiado de Rociana Pedro Martín Calvo durante el año 1593 con algunas interrupciones.

5 Vid. F. Nuñez Roldan, En los confines del reino. Huelva y su tierra en el siglo XVIII, Sevilla, 1987, p.354

6 J:I: Carmona, op.cit., pp.182-183

7 La documentación inédita que he utilizado para este estudio procede del Archivo de la Diputación Provincial de Sevilla (en adelante ADPS),Hospital del Amor de Dios, legajo 3, expedientes 5 y 9 
Cuando Frías llegó a La Palma era ésta una villa de don Francisco del Alcázar,miembro de la poderosa familia sevillana de los Alcázar, usufructuario del mayorazgo que sobre ella fundara en 1531 su abuelo don Francisco del Alcázar caballero veinticuatro y señor de Gelo, quien en 1519 la había comprado junto con el castillo de Alpízar a don Diego Colón, hijo del almirante por la astronómica cantidad de $11.700 .000 \mathrm{mrs}^{8}{ }^{8}$ El itinerario de Hernando Colón de 1517 atribuye a la villa unos 300 vecinos, mientras que el censo general de 1534, que parece más exacto rebaja la cifra hasta 289, (entre los cuales se encontraban 41 pobres, el 14,2 por ciento) ${ }^{9}$. Un padrón del repartimiento de alcabalas de 1546 reduce esa cantidad a 265 vecinos pecheros, volumen de población muy semejante a la de 1534 que incluía a los pobres ${ }^{10}$ Sus dimensiones demográficas eran, por consiguiente, similares a las que tenían otras localidades del entorno ${ }^{11}$ y sus actividades económicas se limitaban a una agricultura de subsistencia aunque con notable ganadería vacuna y ovina. Economía y población que a finales del siglo XVI, en el momento de la reducción hospitalaria, apenas sufrió grandes variaciones.

A los pocos días de su llegada, el 20 de junio de 1590, el doctor Frías redactó una detallada memoria de la visita a La Palma de la que decía que tenía tres hospitales, denominados San Juan, San Blas y Nuestra Señora de la Concepción. Concluida la visita, el visitador dejó la reducción en manos de una comisión presidida por el maestro Pedro Agustín de Sotomayor vicario de la villa y a la que se incorporaron como se establecía en la real provisión tres miembros del cabildo municipal, Antonio de Paredes, alcalde mayor de La Palma y dos regidores nombrados al efecto en la sesión capitular de 17 de mayo de 1591, Antón Rodríguez Gil y Esteban López Godoy ${ }^{12}$. De las diligencias llevadas a cabo por esta comisión se deduce el estado real, económico y asistencial de los tres hospitales, que pasaré a describir.

El hospital de La Concepción, al que según las instrucciones y el parecer del visitador se reducirían los otros dos, estaba situado en la calle Real, junto a la plaza y la iglesia parroquial, en unas casas que fueron medidas y tasadas en el momento de la visita por los alarifes en 500 ducados $^{13}$. Los testigos que informaron

8 Sobre las vicisitudes del señorío pueden tomarse algunas notas en J. GIL, Los conversos y la Inquisición sevillana, 8 vols.,Sevilla, 2000, vol. III, p. 197. Y más extensamente : J. Castizo Reyes, "Una feria para un señorío" en Carta de privilegio de la Real feria de la Palma, 1398-1998, Estudio histórico, paleográfico, diplomático, filológico y lingüistico, La Palma del Condado, 1998, pp.23-66 y especialmente las páginas 49-57.

9 El dato del padrón en J. Castizo, Op. Cit. pp.39-40

10 Archivo Municipal La Palma del Condado (en adelante AMLPC), Actas Capitulares, Legajo 2. Repartimiento de alcabalas correspondiente al ańo 1546.

11 A finales del siglo XVI, Bollullos del Condado contaba con 244 vecinos según el padrón de la moneda forera

12 AMLPC, Actas Capitulares, Legajo 4.

13 ADPS, Hospital del Amor de Dios, legajo 3, expediente 5. 
a la comisión declaraban no saber quién lo fundó, pues no constaban escrituras, aunque se decía que fueron personas laicas quienes lo mandaron levantar a costa de sus bienes; y de oidas de personas de más de cincuenta años se estimaba que se fundó al comenzar el siglo XVI o tal vez antes. Y con respecto a su administración los testigos informaron que se llevaba a cabo por priostes y oficiales de la cofradía del mismo nombre que lo gestionaban, sin especificar cuáles ni cuántos. La hospitalidad de la Concepción consistía en curar pobres que vienen a él enfermos de todo tipo de males para los cuales disponían de seis o siete camas con sus esteras y mantas y una más, muy buena, reservada a un clérigo o fraile que se acogiera a él ${ }^{14}$.

Era por sus ingresos el hospital más rico de los tres, como el propio visitador recordaba en su memoria para razonar la reducción de los demás a él, pues por tributos recibía 11.168 mrs. anuales y por sus propiedades agrícolas, 600 fanegas de tierra de sembradura que se arrendaban, se calculaba que le rentaban 127.160 mrs, lo que sumadas ambas partidas alcanzan unos ingresos anuales de 138.328 mrs, una cantidad que desglosada por partidas permite concluir la enorme importancia que las rentas procedentes de la tierra representan en los ingresos anuales del hospital, o lo que es lo mismo la decisiva intervención del capital agrario que generaba un 92 por ciento del total de las rentas de la institución comparado con la escasa entidad de las rentas financieras si se comparan ambas entradas. Por la información que disponemos de otros hospitales rurales (los de Cazalla de la Sierra, del Puerto de Santa María y de Arcos de la Frontera) éstos de La Palma parecen ser los únicos que poseían tierras de labor cuyas rentas eran fundamentales para sostenerse, aún pasando apuros ${ }^{15}$

El presupuesto para gastos era muy variado: las treinta y seis remembranzas con sus limosnas que estaban obligados a decir y a pagar en memoria por los que dejaron bienes a la cofradía suponían $4.572 \mathrm{mrs}$; la celebración de las fiestas de Nuestra Señora y de san Sebastián costaban $2.259 \mathrm{mrs}$, el salario del predicador cuaresmal se elevaba a $15.000 \mathrm{mrs}$, tal vez la partida más gruesa, si tenemos en cuenta que el hermano mayor tenía de salario $3.750 \mathrm{mrs}$. ,el maestro de escuela cobraba 3.000 mrs. por un trabajo que parece extraño asociarlo a un centro asistencial, y que otros sirvientes cobraban en dinero y especie como el capellán 4.500 y 20 fanegas de trigo, o solo en especie como el casero cuyo oficio le deparaba 12 fanegas de trigo, y el escribano de la cofradía al que se le pagaban 8 fanegas. También se incluyen en las partidas de gasto la vigilia y merienda de los cofrades, de las cuales se omiten las fechas y en las que se estimaba un gasto de 14 fanegas de trigo sin equivalente monetario. Asimismo se incluye como gasto la suelta que

\section{Ibidem}

15 El hospital de San Pedro de Carmona al que se agregaron once hospitales en el momento de la reducción-(1615)-tenía unos ingresos anuales estimados en 258.778 mrs. Vid.: Gómez Martín, M.de C y López Díaz ,M.T., El hospital de San Pedro (1615-1875), Carmona, 1997 pags. 33-43 
los cofrades hicieron a los arrendadores de 26 fanegas de trigo, seguramente por razones de esterilidad, aunque se trataba de una decisión discutible que el mismo Pedro de Frías criticó duramente en su memoria final de la visita. No obstante, era lógico que conocida la hacienda del hospital el visitador concluyera que se redujeran a éste los de San Juan y San Blas por el sitio en el que se ubicaba y por ser más rico .

También el hospital de San Juan estaba situado en la plaza muy próximo al anterior y aunque no disponía de iglesia ni capilla, su casa fue tasada por los alarifes en 300 ducados, de valor netamente inferior a la de la Concepción. Sobre la fecha de su fundación, el clérigo Juan Ramos declaraba que se desconocía aunque por noticia de algunos pleitos se suponía antiguo. Al igual que el hospital de la Concepción, los priostes y cofrades eran los patronos y como tales administraban sus bienes y hacienda al mismo tiempo que nombraban a los oficiales que allí servían. Su hospitalidad, similar al de la Concepción se limitaba a recoger pobres enfermos y curar a los que allí acudían, para los cuales declaraban tener una cama buena para la gente honrada y para los demás sus camas de madera y sus esteras. No obstante, que se incluyera un maestro de escuela en la relación de servidores del hospital revela que al igual que el hospital de la Concepción éste de San Juan también prestaba este servicio de caridad a los vecinos de la villa, fuesen pobres o ricos, extremo que no sabemos. De ser así, indudablemente, la labor meramente asistencial en beneficio de los pobres y enfermos de la comunidad se ve ampliamente superada en el mundo rural por otros servicios sociales a los cuales el municipio no podía o no quería hacer frente. Es por otra parte evidente que estas obligaciones educativas de caridad, si es que se puede hablar así, o de enseñanza de las primeras letras y el catecismo a niños de la villa, tal vez incluidas en las cartas fundacionales, suponían relativamente poco con respecto al total de los gastos del hospital, pues el maestro cobraba en San Juan 1.500 mrs y en La Concepción 3.000 lo que representaba un porcentaje del 14 por ciento sobre el total de los gastos en el caso de San Juan y del 9 por ciento en el de la Concepción.

Las rentas del hospital de San Juan eran más humildes que las de la Concepción: disponía de 88.684 mrs repartidos en tributos (9.395 mrs) y en arrendamientos (79.288mrs) de 231 fanegas de tierra de sembradura, de manera que el peso de la tierra en el capital del hospital al igual que en el caso anterior, fue decisivo a la hora de captar ingresos. La tipología de los cargos era semejante al hospital de la Concepción, pues incluía los sermones de Cuaresma, los salarios del capellán, del maestro de escuela, del escribano y el casero, y del hermano mayor y también las vigilias que hacían los hermanos veintiuna remembranzas por los benefactores del hospital, la celebración de las fiestas de San Juan y San Sebastián.

La información disponible por el visitador acerca del hospital de San Blas era igualmente precisa: el hospital estaba situado en la calle real junto al arroyo de los Cantos y disponía de una iglesia y de una casa junto a ella donde vivía el 
casero que la cuidaba y cuya tasación inmobiliaria fue fijada en 250 ducados $^{16}$ Sobre su fundación aunque era vox populi que había sido erigido por vecinos del lugar de sus bienes y haciendas, no existían escrituras por haberse perdido. Y de la misma manera que ocurría con los otros hospitales, los priostes y cofrades gobernaban y administraban su hacienda sin que nadie les vaya a la mano, una clara expresión de su autonomía con relación a otras instituciones. Autonomía que será el caballo de batalla contra los intentos de reducción, como se verá más adelante.

A diferencia de los otros hospitales, en el de San Blas no se hacía hospitalidad, aunque no por ello se desatendía la curación de los pobres y de los heridos, a lo cual se sumaban otras obras de piedad. En efecto, la atención a los pobres pareció ser su función primordial, estuviesen o no enfermos: por la relación parece que se descarga una partida de 38.935 mrs que dice se gastaron en curar pobres, darles de comer y pagar el médico, llevar de un lugar a otro los pobres que no pueden andar, comprar esteras donde duerman los pobres de donde consta que aunque no tienen hospital hacen hospitalidad ${ }^{17}$. Así pues, las conclusiones de la comisión nombrada al efecto definía la hospitalidad en sentido amplio.

Sus rentas eran muy escasas para atender semejantes fines. En tributos de fincas y casas obtenía anualmente $6.672 \mathrm{mrs}$ una cantidad insignificante si se la compara con las percibidas por ese concepto por el hospital de la Concepción. A esto se sumaban 130 fanegas de trigo en grano y 65 de cebada procedentes de rentas de heredades, lo que indica, a pesar de la parquedad del informe, que el hospital tuvo que disponer de un capital rústico que como en los casos anteriores constituía la fuente y el fundamento material para llevar a cabo actividades como las del socorro de los pobres cuyo solo cargo parecía superior a sus ingresos. No obstante, el hospital, dejaba de ser tal para convertirse en cofradía cuando atendía obligaciones de caridad no estrictamente hospitalarias como la de servir de escuela a los niños pobres pues entre sus nóminas estaba también como en los otros hospitales un maestro de primeras letras al que se le pagaban $1.496 \mathrm{mrs}$ y los demás salarios del presupuesto tenían que ver con los empleados propios de una cofradía: un escribano al que se le pagaba la misma cantidad que al maestro, un hermano mayor y un capellán que percibían 2.244 mrs cada uno y un casero, el más humilde de la nómina, que cobraba $748 \mathrm{mrs}$ y dos fanegas de trigo. La veintena de remembranzas a las que estaba obligada la cofradía y la vigilia que festejaban anualmente tenía un costo significativamente alto $(6.516 \mathrm{mrs})$ pues equivalían poco menos que a los sumados por las partidas salariales $(8.228 \mathrm{mrs})$. Solo la venta en el mercado del grano procedente de los arrendamientos lograría sanear las cuentas, presumible y frecuentemente deficitarias. Pero fue la pobreza

16 Casero y no ermitaño lo cual distingue la función de la iglesia.

17 ADPS, Hospital del Amor de Dios, Legajo 3, expediente 5. 
de sus rentas y su escasa función asistencial lo que movió al visitador a pedir su reducción a un hospital mayor, el de la Concepción.

La reducción llevaba aparejada no sólo la desaparición de los hospitales de menor entidad económica y asistencial, San Juan y San Blas, sino también la incorporación de sus bienes, rentas, derechos, acciones y propiedades al de la Concepción que a cambio tendría que modificar sus reglas y constituciones, disponiendo de unas nuevas conforme a los designios de los breves papales. Parecía lógico que a la conclusión de la visita se aplicaría la decisión razonada del visitador, emitida en febrero de 1592, pero en el caso de La Palma habían aparecido antes de esa fecha fuertes resistencias que impedirían llevar a cabo la reducción. Más adelante nos ocuparemos de ellas.

\section{La REDUCCión de lOS hospitales EN Niebla}

Ignoramos la razón por la cual el doctor Frías no visitó Niebla, como él mismo apuntó en su memoria final, ni se le comisionó para llevar a cabo la reducción de sus hospitales. La explicación habrá que encontrarla en el expediente final de la misma en el que se incorporó una carta del duque de Medinasidonia enviada al licenciado Maseda, mayordomo del cardenal hispalense, recomendando a la persona que podría llevar a efecto la misión ${ }^{18}$. Es obvio, por su letra, que el duque, señor de la villa y de su condado, favoreció la reducción y propuso a quien la habría de ejecutar:

Como ofrecí a vm en la passada de avisarle el clérigo a quien su señoría ilustrísima a de dar comisión para las diligencias que se han de hacer juntándose con el corregidor y regidores de Niebla para la reducción de los hospitales de aquella villa me parece que Pedro Martín Calvo cura de Rociana que es de la misma vicaría de Niebla y su aldea hará muy bien las diligencias porque es persona de pecho y letrado y su señoría ilustrísima le conoce bien por haber con su licencia fundado un monasterio de monjas a su costa en la dicha Rociana. Escribo al corregidor de aquella villa con la advertencia de lo que habrá de hacer. Vuesa merced le mande encaminar el pliego donde fueren los demás recaudos y la brevedad importará por muchos respetos del servicio de Nuestro Señor que guarde a v.m como deseo. En Sanlúcar a 4 de marzo de 1591

El duque de Medina Sidonia.

Al contrario de lo que sucediera en La Palma donde el vicario, el maestro Sotomayor, fue nombrado para formar la comisión municipal de la reducción por el visitador Frias y no por don Francisco del Alcázar, la designación de Pedro 
Martín Calvo por parte del duque favorece la idea de que no todos los señores jurisdiccionales actuaron de la misma manera en el proceso de la reducción. Y es significativo al respecto también que el designado para presidirla fuese un cura de un lugar próximo, piadoso, recto y de formación, que, además, tuvo problemas de salud durante el tiempo que se ocupó de la tarea. Pero sea como fuere, la comisión elevó al arzobispado la resolución de las diligencias hechas en Niebla y la propuesta de reducción a uno de los cinco con los que contaba la villa a mediados de febrero de 1593, dos años después del inicio del proceso.

El primero de los hospitales a reducir en Niebla, a propuesta de la comisión formada por Pedro Martín Calvo, por el licenciado Barrionuevo, corregidor del condado, y de los regidores de la villa el licenciado Martín Ramírez y Andrés Gallegos, fue el de San Nicolás. Estaba situado en una casa en la collación de san Martín en la calle que iba a la plaza. Tasada por los albañiles y alarifes en 200 ducados, la casa seguía el modelo hispalense : tenía una casapuerta, un corredor $\mathrm{y}$ tres aposentos, de los cuales uno era para echar pan, es decir, con horno o como granero, y otro para fuego, tal vez pensado para el invierno por tener una chimenea. No faltaba un patio con un membrillero y un corral con sus árboles. Aunque no constaba documento de fundación era opinión en la villa que lo fundó Domingo Martín, clérigo, y por esta razón su gobierno y administración dependía de los clérigos cofrades de la villa que nombraban para ello sus oficiales y sus cargos (un prioste y un abad). En sus reglas el fundador mandó que se celebrara una fiesta principal el día de San Nicolás en el que los clérigos cofrades nombraban un obispo y este habia de ser muchacho moço lego y un abad y un arcediano y el día de San Nicolás lo llevaban en procesión a la iglesia y lo volvian al hospital y daban colación al pueblo, ansi pobres como ricos ${ }^{19}$. Pero, como ocurrió en otros lugares, la fiesta fue prohibida por un auto dictado en 20 de noviembre de 1572 por el visitador licenciado Salazar. La hospitalidad de San Nicolás consistía en tener una cama para los clérigos y frailes que pasaban por Niebla aunque por la relación hecha por el mayordomo Hernando García el hospital recibía a todos los peregrinos, fuesen o no clérigos, a quienes les daban uno o dos reales para su gasto, si bien, algunos testimonios negaban que esta limosna se diera.

En lo económico, el hospital de San Nicolás apenas tenía cargos que cumplir y los que parecían como tales, algunas cláusulas testamentarias y una fiesta a la Virgen, no estaban documentados. Por las rentas que declaraba se trataba de un hospital relativamente pobre: tenía una casilla cuyo arrendamiento anual le rentaba $1.500 \mathrm{mrs}$, en tributos perpetuos sobre tierras de pan obtenía $9.295 \mathrm{mrs}$ $y$ en especie por conceptos que no se concretaban, aunque se entiende que por el arrendamiento de 301 fanegas de tierras propias y atributadas 133 fanegas de trigo y 66 de cebada. De manera que los gastos no podían ser muy gruesos: estaba 
obligado el hospital a gastar $10.404 \mathrm{mrs}$ en misas por cincuenta y un aniversarios que se decían en las tres parroquias de Niebla (Santa María, San Martín, Santiago) y en la fiesta de san Martín gastaba 1.360 mrs de carne y seis fanegas de trigo de pan amasado para dar de comer a los pobres. Además, se incluía entre sus partidas de gasto $18.170 \mathrm{mrs}$ que se daban a doncellas pobres para su casamiento Las partidas salariales se reducían a dos y manifestaban no solo su pobreza sino su escasa tarea asistencial: un mayordomo percibía 2.000 mrs y el hospitalero 1.122 mrs. Por esta precariedad y por razón de obediencia dado su carácter clerical, los cofrades de San Nicolás declararon tener por buena y santa la reducción ${ }^{20}$.

Más pobre aún era el hospital y cofradía de San Sebastián, una advocación tan común en todo el territorio del condado de Niebla y en la villa de Huelva, seguramente por influencia ducal. Situado en la parroquia de Santiago, tenía su casa muy pobremente tasada en 60 ducados, lindera con la del vicario de Niebla Alonso Martín. Con respecto a su fundación se ignoraba quién lo hizo, aunque según los testimonios recogidos por la comisión podría haber sido un tal Antón Martín quien donó su casa para que sirviera de hospital con la obligación de que le dijesen una misa aniversario el día después de san Sebastián. Se trataba de un hospital asociado a la una cofradía de vida apagada por las fechas de la reducción que lo gobernaba mediante un alcalde, un mayordomo y diputados. Aunque hacía hospitalidad que consistía en el traslado de los pobres tullidos de un lugar a otro, y en recogerlos en la casa para lo cual disponía de unas mantas y unas esteras de eneas en las que dormían algunos pobres, sus rentas eran muy cortas.

En efecto, por las cuentas que presentó la comisión se trataba de un hospital muy pobre, tanto que no tenía personal asalariado (aunque se incluye un gasto sin adjudicación nominal de 7 ducados de salarios) y unos cortos ingresos de 3.036 mrs de renta anual en concepto de tributos sobre unas viñas y partes de casas de poca consideración, más 47 fanegas de trigo y poco más de 10 fanegas de cebada que procedían del arrendamiento de 132 fanegas de tierras propias que servían para cumplir con las obligaciones de veintiocho aniversarios de misas cuyo gasto se elevaba a $6.000 \mathrm{mrs}$ y la procesión solemne el día del santo que costaba $1.448 \mathrm{mrs}$ La escasa o nula hospitalidad que hacía y su pobreza determinó a los testigos que colaboraron con la comisión a seguir en la línea trazada de recomendar su reducción.

Parecía de semejante entidad y pobreza el hospital de la Misericordia sito en una casa de la collación de Santa María en la calle del Arco tasada en 80 ducados. $\mathrm{Su}$ fecha de fundación parecía remontarse a finales del siglo XV o comienzos del XVI como se pretendía demostrar por una escritura notarial en pergamino del año 1501 ante Alonso Delgado escribano público de Niebla, por la cual los cofrades compraron una casa para hacer hospital, que en la fecha de la reducción era la que habitaban. Como aval de su antigüedad presentaron los cofrades tam- 
bién una confirmación notarial de la regla de la cofradía firmada en los palacios arzobispales 3 de septiembre de 1519 ante Antón de Mora por el licenciado Flórez provisor del arzobispado, de manera que, de todos los hospitales, éste parece ser el único del que puede señalarse fecha aproximada de fundación. Su pobreza era tal que no tenía capacidad para ofertar hospitalidad, sino el coste del entierro de los que morían muy pobres, razón suficiente además para someterlo a reducción Un hermano mayor elegido por los cofrades gobernaba el hospital cuyos ingresos se limitaban a $8.373 \mathrm{mrs}$ procedentes de la renta de algunas casillas y tributos sobre tierras y a 15 fanegas y 8 almudes de trigo y 4 almudes de cebada que procedían del arrendamiento anual de 26 fanegas de tierras propias que apenas parecían suficientes para afrontar los cargos que consistían en decir treinta y un aniversarios de misas en las iglesias de Niebla, que alcanzaban los 5.324 mrs anuales, en cumplir con las tres pascuas del año, en las procesiones de los terceros días después de cada una de las pascuas, y en pagar los salarios anuales de $2.500 \mathrm{mrs}$ al casero, mayordomo y escribano. No es extrańo, conocidas las dificultades económicas y patrimoniales que padecía, que los testigos que declararon ante la comisión apostaran también en este caso por la reducción del hospital.

El cuarto de los hospitales de Niebla, el de San Martín, fue fundado,según algunos testigos que depusieron ante la comisión, por Alonso Martín Parrales y su mujer Inés Jiménez a principios del siglo XVI. Otros testigos, en cambio, acudían a una bula de León X dada en noviembre de 1509 en la que los cofrades declaraban estar obligados a decir cinco misas semanales por el alma de aquellos y que lo que sobrare se destinara al sustento de los pobres, lo cual no acreditaba la fundación sino únicamente la antigüedad de la cofradía, que desde aquel tiempo gobernaba y administraba el hospital. Su finalidad consistía en recibir pobres peregrinos en una casa que, valorada en 150 ducados, daba mucho más de sí que la de ser un mero albergue, pues tenía 42 varas de perímetro, con un corral de 28 varas y un patio con doce arcos y con aposentos altos y bajos, tasada en 150 ducados. Sin embargo solo disponía de cuatro freçadas sin cama ni otra ropa y cuatro medias esteras Era lógico, en consecuencia, que sus rentas fuesen tan limitadas: 7.704 mrs y 154 fanegas de trigo y 66 fanegas y 2 almudes de cebada que producía el arrendamiento de 592 fanegas de tierra propias. Con estas pobres rentas el hospital atendía el cargo de las misas por sus fundadores que se decían en la capilla del Cristo atado a la columna de la parroquia de San Martín cuyo capellán percibía por las mismas 60 ducados. Celebraba dos fiestas la cofradía, una por San Martín y otra por San Mateo y en ambas había procesión, víspera y misa y, no siempre, sermón. Alcanzaban sus rentas para pagar al mayordomo 4.000 mrs y al casero $4.522 \mathrm{mrs}$, al escribano 2 fanegas de trigo y lo que quedaba de la renta se destinaba a curar pobres del lugar, casar huérfanas, pagar a un maestro que enseñaba a leer y a escribir a los niños en la casa propiedad del hospital que se tasó en 150 ducados. 
A la vista de las cortas rentas que poseían y de la carencia de hospitalidad y de asistencia que ofertaban, los cuatro hospitales se redujeron al de Nuestra Señora de los Ángeles por ser más antiguo, de más devoción y de mejor sitio y edificios, como entendía la comisión. Tenía el hospital su casa en la collación de la iglesia mayor, haciendo esquina de la plaza de Santa María, y lindaba con la calle que llamaban de los Doctores y con casas de Francisco Rodríguez Avendaño ${ }^{21}$. Tenía el hospital en su interior una capilla mayor de ntra sra de mucha devoción y una portada que sale a la plaza que dicen es suntuosa y con una imagen de devoción, tal como hoy se conserva. Los maestros alarifes la tasaron en 200 ducados aunque valdrá más apostillaron los visitadores de la comisión en su expediente. Y seguramente era cierto porque tenía, aposentos altos y bajos, y los del fuego con sus chimeneas, y patio con su pozo y pila y la capilla donde se dice misa. La tradición decía que fue fundado el hospital por unos caballeros que vivían en Niebla siendo realenga, es decir, a comienzos del siglo XIV. Era opinión común también que una vez que la villa se convirtió en la cabecera del condado, los caballeros se trasladaron a vivir a Jerez $y$ dexaron al hospital parte de su hacienda. Constituida en cofradía con el nombre de su advocación, eran sus miembros quienes gobernaban y administraban el hospital cuya labor consistía en recoger a los pobres sanos que vienen de fuera y les dan unas esteras y mantas en que duermen y ai una cama con colchones, sábanas y almoadas para curar enfermos ampliando su asistencia a los pobres vergonzantes naturales de la villa, extremo en el que algunos testigos se contradecían al responder el interrogatorio de la comisión.

A pesar de que los otros hospitales fueron reducidos a éste, sus rentas no parece que fueran sustancialmente diferentes en cantidad con respecto a los otros en el momento de la reducción, aunque a juicio de los componentes de la comisión fuese un factor decisivo a la hora de tomar la decisión final. Cortas eran las rentas del hospital de Ntra Señora de los Ángeles porque, a pesar de que doblaban en algún caso las de los demás hospitales iliplenses, si las comparásemos con las que obtenían los de La Palma parecen ridículas y esto explicaría en parte por qué tuvo éxito el proceso de reducción hospitalaria en Niebla y porque fracasó en La Palma, cuestión que tendremos ocasión de tratar más adelante. Las rentas de Ntra Sra de los Angeles consistían en 16.768 mrs y medio en dineros y 686 fanegas de tierra atributadas que le proporcionaban anualmente 192 fanegas de trigo y 131 fanegas de cebada aunque por las condiciones de los contratos se reducían en tiempos de esterilidad a la tercera parte en granos y las dos partes restantes a cinco reales la fanega de trigo y a 3 reales la cebada. Así pues, como ocurría en todos los centros asistenciales rurales, los tributos sobre casas o fincas y el arrendamiento

21 La casa hospital cuya portada es de estilo gótico mudéjar se conserva en su antiguo emplazamiento y da sabor a la esquina de la plaza en la que se encuentra la iglesia de Santa María la Granada del mismo estilo. 
de tierras de sembradura propias o atributadas constituían el soporte material del sistema hospitalario ${ }^{22}$.

Sus obligaciones se reducían a cumplir con ochenta y cuatro aniversarios de misas en las iglesias de Niebla y con otras de voluntad del propio hospital, por todo lo cual se pagaban $9.877 \mathrm{mrs}$, una cantidad que sangraba la mitad de sus ingresos en dinero anuales y que limitaba drásticamente la labor asistencial, como ocurría en los otros hospitales estudiados. Los salarios al mayordomo (4.496mrs), al escribano ( $4.862 \mathrm{mrs}$ ) y al casero (1122 mrs y 6 fanegas de trigo), completaban el capítulo presupuestario que a falta de una contabilidad detallada suponemos que agotaba los ingresos de la institución. Se trata, por otra parte, del único hospital que presenta un breve inventario de sus bienes muebles, concretamente los necesarios para decir misa en la capilla de su casa: una casulla, alba y lo demás necesario, un cáliz de plata, dos misales, un ara de jaspe, dos candeleros y una lámpara de açofar y unos manteles para el altar, que se usaban en las misas aniversarios por los fundadores o en las solemnes a que estaba obligado en las fiestas de la Asunción, San Lorenzo y San Miguel.

\section{ResistenCias DEsiguales}

El 30 de julio de 1591 la comisión formada en Niebla finalizó su trabajo y propuso la reducción de los cinco hospitales al de Nuestra Señora de los Angeles. Sin embargo, la resistencia ofrecida por los cofrades de San Martín, sobre la base jurídica de que no se puede reducir por ser como es patronazgo de legos, retrasó el proceso al menos hasta 1602, en cuyo mes de febrero el duque de Medina Sidonia instaba al visitador a que acabe la reducción. Es muy probable que sin su intervención el pleito que la cofradía de San Martín presentó en 1598 ante la Real Audiencia de Sevilla hubiera aplazado durante varios años más el cumplimiento de la política real. Ignoramos el fallo de la Audencia hispalense al pleito presentado por la cofradía, pero es seguro que la voluntad del conde de Niebla alineándose con la política real se impuso finalmente ${ }^{23}$.

Por el contrario, las resistencias que se produjeron en La Palma dieron su fruto pues la reducción hospitalaria no se llevó a cabo y los hospitales tuvieron tan larga vida que no desaparecieron hasta otro proceso de reducción, en este caso, de época liberal, el que redujo los hospitales del Antiguo Régimen al sistema de beneficencia pública dependiente del municipio. Es lo que hace historiográficamente interesan-

22 Su capital inmobiliario pudo haberse incrementado a comienzos del siglo XVI si María Farfán vecina del lugar no hubiese revocado la donación que le otorgó de unas casas situadas en la collación de Santiago en la calle de Los coperos. La revocación tuvo lugar en 10 de marzo de 1531 porque la donante, ante la ausencia del marido, ausente en Indias, declaraba que ha menester las dichas casas e disponer de ellas. El documento en Archivo Histórico Provincial de Sevilla, Protocolos Notariales, legajo $17.463 \mathrm{~s} / \mathrm{f}$

23 ADPS, Hospital del Amor de Dios, legajo 3, expediente 9. 
te el caso que nos ocupa: ‘acaso la odisea que protagonizaron los hospitales de La Palma hasta llegar a 1847 no representó, conociendo la asistencia social prestada, sino el fracaso de la política unificadora que hubiera impedido su desarrollo con mayor o menor acierto y eficacia? Trataré de responder más adelante.

Los responsables de las cofradías amenazadas de reducción en La Palma a los que se sumó la del hospital que había sido elegido para sobrevivir, La Concepción, apenas el visitador se hubo ido de La Palma, apelaron sus mandatos ante la Audiencia Real de Sevilla en 6 de julio de 1591, argumentando que aquél les había prohibido dar limosnas, les ponía limitaciones para hacer sus fiestas y les había rechazado una apelación que le habían presentado. El visitador Frías se defendió respondiendo ante tres testigos vecinos de la villa que él no les estorbaba el hacer de sus fiestas, sino el mal uso y costumbre que tienen de comer a costa de los hospitales y cofradias y que haya buena cuenta y razón porque de ellas consta su mala orden ${ }^{24}$. El visitador apelaba, pues, a la corrupción de los responsables hospitalarios que habían alterado el sentido original de la función asistencial como la razón última de la reducción, lo cual no coincidía en todo con el espíritu y la letra de la real provisión del rey que razonaba la reducción sobre la base de dos motivos fundamentales: el número excesivo de hospitales repartidos por el reino y su precariedad financiera, incapaces de llevar a cabo una hospitalidad a favor de los pobres. Sin embargo, los cofrades siguieron adelante con su decisión de apelar a la Audiencia y consiguieron sus propósitos, pues los oidores Fernández de Córdoba, Rojas de Carvajal y Vernuy admitieron su apelación y dictaron que el visitador debía no solo aceptarla sino también retirar los mandatos de la visita, amén de anular el proceso excomulgatorio que había iniciado contra ellos. En ese contexto se entiende muy bien el tenor de la carta que el vicario de La Palma dirigió al doctor Frías advirtiéndole de las dificultades de la reducción pocos días después de la visita y antes de que los cofrades se personaran ante la Audiencia:

Los hermanos mayores de las cofradías desta villa de la Palma andan muy enojados por los mandatos que v.m. les dexó y en seguimiento de la apellaçión que hizieron truxeron una apellacion del Audiencia Real de Sevilla la qual me notificaron cuyo traslado es el que con esta va. Dizen que otros arzobispos de Sevilla han querido reducirlos y no an podido y ansí dizen no se podrá hazer agora reducción de ellos. Todo su enojo es conmigo porque no disimulo con lo que quieren hacer aunque yo no e declarado a ninguno por excomulgado porque no e sabido aya quebrantado algo de los mandatos de v.m. pero eles amenazado açerca de las obladas que andan aderezando para dar el día de la Degollación de san Juan que si lo hazen 
les e de excomulgar. Plegue a Dios que el me saque de gente tan indómita. V.m. vea lo que se a de hacer en esto y me lo mande que obedeceré a v.m. como súbdito y en mi conçiençia que sería servicio muy acepto a ntro señor oy antes que mañana reducirlos. Esto es lo que siento. Dios guarde a v.m. largos años y le ponga en la dignidad que mereçe y yo su cappellán le deseo. De la Palma junio de 1590 años- El Maestro Sotomayor ${ }^{25}$

Tanto la respuesta de Pedro de Frías a los cofrades como su empeño en llevar a cabo la reducción se fundamentaban en un examen riguroso y objetivo de la situación de los hospitales del cual se concluía una pésima gestión de los mismos por parte de administradores y hermanos mayores y, especialmente unas corruptelas escandalosas probadas por el visitador no solo en La Palma sino en otros lugares vecinos y ante las cuales no estaba dispuesto a ceder, pues constituían una razón más que moral para justificar la tarea que se le había encomendado. Su misión parecía cumplida cuando pensó que la reducción a la que obligaba a los hospitales se ejecutaría de inmediato, pero no contaba con la resistencia y con el sentimiento de autonomía de las cofradías con respecto a otras jurisdicciones, incluso la eclesiástica. Pensó que amenazar con la excomunión sería suficiente para doblegar a aquella gente indómita y terca, espoleados por la experiencia de haber ganado pleitos y pulsos a la autoridad arzobispal por la misma causa que ahora se les presentaba. Para frustración del visitador las cofradías ganaron el pulso final en los estrados, aunque no tengamos el fallo que lo certifique y que lo fundamente. Es una incógnita, no obstante, que en dos lugares tan próximos el resultado y la eficacia de la política reductora fuese tan diametralmente opuesta. Habría que buscar entre las causas, en primer lugar, la diferente interpretación judicial ante los pleitos presentados por los demandantes, consistentes y múltiples en La Palma, aislado e individual en Niebla. En segundo lugar, la desigualdad patrimonial en un lugar y otro de los hospitales: en La Palma, ricos, en Niebla pobres, en La Palma, en consecuencia, con mayor capacidad y autonomía para sobrevivir y en Niebla necesariamente abocados a la desaparición de los pobres a favor del considerado más fuerte para mantener e incrementar la labor asistencial. Sería una tercera razón la desigual posición de los señores de cada lugar respecto a la reducción: apoyo a los rebeldes por omisión y silencio del señor de La Palma y colaboración con los delegados regios por coincidencia de intereses o por obediencia por parte del señor de Niebla el duque de Medina Sidonia que acabó imponiendo su voluntad a la débil cofradía de San Martín que se resistía con la esperanza de ganar el pleito en los juzgados, a imitación de sus semejantes de La Palma. 


\section{UNA PÉSIMA ADMINISTRACIÓN}

En realidad, desde que partió de Sevilla el visitador Frías no dejó de toparse con un sinfín de problemas allí por donde pasó a inspeccionar hospitales. No obstante, al volver a la ciudad redactó una memoria de cuya lectura se interpreta que la situación hallada en La Palma fue para él lo suficientemente representativa de lo que ocurría en el resto de los lugares visitados, porque además de los casos de corrupción de las reglas fundacionales que les obligaba a la asistencia de los pobres, sus administradores llevaron a cabo una pésima gestión del patrimonio de las instituciones asistenciales que en algunos casos terminaba por favorecer a los propios cofrades que las gobernaban.

En La Palma el visitador desplegó una intensa actividad investigadora que comenzó por la rendición de cuentas del mayordomo:

...en la visita que hice de ellos en veinte de junio deste año de noventa , hallé que a Pedro Martín Candón mayordomo que fue del hospital de San Blas en las cuentas que había dado del tiempo de su administración se le pasaron en cuenta muchas partidas gruessas de gastos que dixo haber hecho sin mostrar conocimientos_de las personas a quien dice haberlas pagado y también se descargaba de cantidad de frisa y otras cosas que decía haber comprado para dar de limosna sin declarar a quién ni cómo ni con qué orden las había repartido y en las demás cuentas deste y los otros dos hospitales hallé otras partidas que daban sospecha de mala administración de los mayordomos como por los libros de sus cuentas parece a que me refiero ${ }^{26}$.

La auditoría de Frías no solo se detuvo en el análisis de la contabilidad o, mejor dicho, en su inexistencia, relacionada tal vez con la rusticidad y la falta de rigor contable de estas cofradías. El visitador pretendía ser firme e insistía fundamentalmente en la falta de honestidad de los mayordomos que no solo favorecían a quienes formaban parte de las cofradías, como organismos cerrados, sino entre ellos mismos, manipulando los alcances de las cuentas:

Juntose a esto la fama pública que en aquella villa ay de que los dichos mayordomos convierten en su utilidad particular_mucha parte de la hazienda de los pobres y que a los cofrades se arriendan las posesiones de los hospitales y al tiempo de pagar los arrendamientos se hacen suelta de mucha parte del trigo y dineros que deben pagar y también hacen remisión a los mayordomos de parte de los alcances que se les hacen cuando se les toman cuentas como por ellas parece ${ }^{27}$. 
Entendían los vecinos no afectos a las cofradías que éstas disponían del patrimonio de los hospitales para su usufructo y beneficio privado. La práctica era denunciable pero nadie paró ante el visitador arzobispal para concretarla, de tal manera que no parecía condenable por la opinión común, más próxima al proverbio castellano dicho con las palabras del revés: quien tañe las campanas, lleva las obladas. Pero, habituado a estos rumores entre los vecinos que voceaban la impunidad y las corruptelas de los administradores de estas y otras instituciones rurales, Frías pensó que, aunque bastaba tener yo noticias de estas cosas en la manera que he dicho para ordenar lo que me pareciere conveniente para remediar estos abusos, ${ }^{28}$ sería más objetivo acudir a una rueda de testigos para corroborar unas acusaciones que también podrían ser falsas.

De los cuatro testigos interrogados, el presbítero de la villa Juan Díaz y el escribano de los mismos hospitales fueron los que más justificaron las sospechas del visitador. El primero denunció

que los dichos hospitales tienen mucha renta y que se gasta entre los cofrades mal gastada, porque no luce nada y que los alcances que se hacen a los mayordomos no se cobran y se hacen sueltas unos a otros de lo que deben a los hospitales y entre ellos se arriendan las posessiones tomándolas en mucho menos de lo que valen y que convendría al servicio de Dios se remediasse esto ${ }^{29}$.

No obstante, por su mayor y más cotidiano conocimiento de la administración de los hospitales parecían más valiosos los testimonios de Diego Moreno de Lara escribano de los hospitales quien declaró

que se murmura en la villa que los mayordomos no lo hacen bien en el repartir de las limosnas, ni guardan la orden que conviene y que esto procede de que algunos hermanos mayores dan las limosnas a quien les parece y a sus deudos y parientes y dexan de darles a los pobres necesitados y que a Pedro Martín Candón se le hizo suelta de una parte del alcance del tiempo que fue mayordomo como parece por las cuentas y que a los cofrades se arriendan las tierras por pregón a quien más da y después se les hacen sueltas en ańos estériles de parte de los mrs y trigo que son obligados a pagar y esto con acuerdo del cabildo ${ }^{30}$ 
Ante semejantes denuncias, al visitador solo le cabía redactar los mandatos y trasladarlos a sus superiores. Pero un pequeńo episodio incluido en los testimonios del sacristán de la parroquia, Pedro García, casi una anécdota, tal vez irrelevante moralmente para otros, no pasó desapercibida para Frías. Al ser interrogado sobre la forma de conducirse del mayordomo de San Blas, el sacristán declaró que habiendo ido él en nombre del vicario a cobrar una deuda de 8 reales que el hospital le debía por el sermón que predicó el día de la fiesta principal del hospital, el mayordomo le dio solo siete reales y que ni él ni el vicario le extendieron conocimiento o recibí alguno y tampoco el mayordomo, como parecía ser la práctica, se lo pidió. Y al reclamársele el real que quedaba debiendo, el mayordomo se excusó del impago diciendo que no había dineros a pesar de que en los libros de cuentas se anotó la partida del gasto sin detallar el receptor. Se trataba tal vez de un insignificante descuido del mayordomo, dada la familiaridad propia de las relaciones económicas en el mundo rural donde era común diferir pagos sin que mediaran adeudos. Sin embargo, el visitador lo interpretó como algo más que un defecto de procedimiento y lo que era insignificante o lo parecía, se mostró para él como una expresión de una actitud inmoral digna de corregir:

Aunque parece cosa menuda lo que el vicario y el sacristán deponen del real que le dieron menos, es de mucha consideración, porque quien hurtó en aquella partida un real y en las quentas hizo poner fe de haber mostrado conocimiento, siendo esto falso, avrá hecho lo mismo en otras summas y particularmente en las de las limosnas en que no se declara a quien se dieron ${ }^{31}$.

Los mandatos del visitador al término de la visita a La Palma fueron redactados atendiendo a todas estas prácticas desordenadas, abusivas, y descuidadas comunes a todos los hospitales. Ordenó, por consiguiente, que se ajustasen las cuentas de la mayordomía de San Blas, no admitiéndole en descargo las partidas que hubiese gastado sin orden del cabildo de la cofradía y de las que no hubiese mostrado conocimientos. Igualmente, amparándose en el rumor que corría en la villa y en la comarca de que no se reparten las limosnas con la rectitud y consciencia que es razón mandaba que los mayordomos estuviesen acompańados en el momento del reparto entre los pobres por el vicario o por uno de los curas del lugar, de manera que consiguió, además, la intervención y la participación de representante eclesiástico en una de las funciones propias de los hospitales laicos. Abundó en esta cuestión, que le parecía prioritaria por lo que suponía de modelo de conducta pública de una institución con fines caritativos, al obligar a los mayordomos que 
por cuanto en las cuentas se da descargo de quantidad de pan, vino y queso que los días de las fiestas de los dichos hospitales gastan los cofrades y reparten entre si con que solemnizan las fiestas lo qual no resulta en deservicio de ntro seńor y veneración de sus sanctos, pero es cosa de mal exemplo y daño de los pobres a quien se quita lo que se gasta en esta superfluidad, que de aquí adelante los mayordomos no hagan este gasto sopena que será a su costa ${ }^{32}$.

Sin olvidar los aspectos disciplinarios, no dejó el visitador de ofrecer soluciones a la vista de tantos problemas. Para corregir los defectos que se le habían denunciado en el capítulo relativo a la gestión del patrimonio rústico de los hospitales por parte de los mayordomos y cofrades, a los cuales se les acusaba de que se arrendaban las tierras entre ellos y al cabo del arrendamiento se hacen sueltas de los mrs y trigo que deben pagar, Frías apuntó que en adelante no se hiciesen las dichas sueltas, es decir, que no se perdonaran las deudas, si no fuese juntando el cabildo de la cofradía, para evitar acuerdos opacos y privados, y con aprobación de la mayor parte de los cofrades; y en el caso de una remisión consentida por todos, sugería el visitador que la cantidad de que se hiciere suelta no excediese de la renta de un año, al mismo tiempo que apuntaba, para evitar tratos de favor continuados, que el arrendatario a quien se hiciere esta remisión dejara la posesión que tuviere arrendada, arrendándose a otro y guardando en el arrendamiento la solemnidad del derecho ${ }^{33}$.

Así pues, Frías no dejaba nada al azar, ni al capricho de la corriente o de las costumbres por muy asentadas que estuviesen. Pero la otra cara de la moneda es que las faltas observadas en La Palma no eran excepcionales sino comunes a todos los hospitales de la comarca y de más allá, como el mismo Frías, decepcionado, pudo experimentar y considerar al final de su periplo por las villas que fue recorriendo a lo largo del camino que unía Sevilla con Ayamonte.

\section{UN MAL GENERAL}

Sus observaciones constituyen un análisis detallado de los problemas que aquejaban al sistema hospitalario rural a finales del siglo XVI e independientemente de la casuística que presenta, el retrato es general como él mismo advertía en las primeras líneas de su memoria. Lo que se ha dicho de los hospitales de La Palma de la mala administración y poca hospitalidad que hacen pasa de la misma manera en otros lugares que he visitado, escribía el visitador en su memoria final firmada y sin fecha ${ }^{34}$. No obstante, trazó un mapa de los males y se remitió a las

34 Ibidem. El informe está junto al que el propio Frias por una parte y la comisión municipal 
soluciones apuntadas en La Palma, cuya situación constituía un paradigma al que remitirse sin necesidad de conocer todos y cada uno de los casos. No obstante, no está demás que siguiendo su propio memorándum conozcamos las carencias y los males de aquellos hospitales en el momento de la reducción.

La visita a Sanlúcar la Mayor una gran villa del Aljarafe hispalense, la primera en el camino que conduciría a Frías por las tierras del sur onubense en el verano de 1591, descompuso su ánimo y le dejó un mal presagio, pues habiendo sido visitada un año antes por el licenciado Francisco de Aguiar, nada parecía haberse corregido desde entonces. Lo grave no era para Frías el hecho de que sus hospitales a pesar de tener mucha renta no disponían de una sola cama donde curar un enfermo. Peor era la conducta rebelde de sus administradores que hicieron caso omiso de los mandatos que les dejó Aguiar por lo cual pasé ligeramente por la visita de aquellos hospitales sin dexar mandatos ningunos para obviar a las dichas desórdenes pues no los habian de obedeçer como no han obedeçido los de otros visitadores que están en los libros de sus cuentas y ninguno se ha cumplido y pareçiome era menos inconveniente no mandar cosa ninguna que darles materia para que desobedezcan ${ }^{35}$.

Es incuestionable que Frías y tal vez los demás visitadores detectaban una pérdida notable del principio de autoridad que representaban y ante la cual cabían dos posiciones: o cumplir con el mero deber de detectar los problemas y denunciarlos o ir más allá y corregirlos mediante la disciplina y el rigor. Frías seguramente pesimista estaba entre los primeros.

Al pasar a Paterna el visitador advirtió que los mayordomos de los hospitales repartian por Navidad paños y otras cosas de vestidos, aunque los beneficiados no eran los pobres sino sus criados y esclavos y otras personas que de ellos y de sus amigos dependen, dexando desnudos a los más necesitados ${ }^{36}$. Ponía en evidencia Frías el egoísmo de los que utilizaban el patrimonio destinado a socorrer a los pobres en beneficio privado. Esta dosis de evangelismo está presente en todo su periplo pero no deja de ser inútil si se atiende a los resultados.

En Escacena, en cambio, el motivo de su preocupación no fue otro que la noticia que le llegó acerca de una mugercilla forastera que estuvo unos meses en el hospital haziendo del albergue de los pobres de Dios casa de deshonestidad, aunque pocos días antes de que Frías llegase a visitar se habia huido ${ }^{37}$, seguramente avisada por un vecino compasivo o interesado.

Más grave fueron los males detectados en Almonte en cuyo hospital no se cobraban los alcances de muchos años atrás que los mayordomos deben y mandé que pagasen dentro de cierto término sopena de escomunión y di comisión al cura más an-

de La Palma por otra redactaron acerca del proceso de la reducción.

35 Ibidem

36 Ibidem

37 Ibidem 
tiguo para que lo essecutase el cual me ha escrito que algunos han pagado y otros apelado para el provisor ${ }^{38}$. Las resistencias eran aquí tan evidentes como las corruptelas que denunciaba Frías, quien trajo a su informe un caso concreto, un modelo de actuación de los responsables de las cuentas de estos centros asistenciales dejados de la mano de Dios:

Y estaban muertos (sic) de un hospital treinta y tantos mil mrs que devía un sacristán de la iglesia de aquella villa del tiempo que fue mayordomo con los cuales entonces edificó una casa y pareçiole cosa tan nueva y fuera de razón que le mandase pagar que dixo que era lego y que había de apelar para la audiencia y hubiéralo hecho si no se recelara que podrían quitarle la sacristía y assí me escriben que quiere tomar dineros a tributo para paga ${ }^{39}$.

Parecía inaudito a ojos del sacristán que alguien le recriminase su conducta inmoral e improcedente, construirse una casa, incrementar su propio patrimonio con los dineros de un hospital. Parecía inaudito y nuevo también a ojos del visitador que malversar los caudales asistenciales se hubiese convertido en costumbre entre los dirigentes hospitalarios sin que nadie entre los propios vecinos que asistían como espectadores pasivos a tamaños atropellos acudiese a denunciarla. Pero lo que más inaudita y nueva parecía era a ojos de los mayordomos la conducta rigurosa y recriminatoria del visitador. Por otra parte, la argucia legal esgrimida por el sacristán de ser lego para oponerse a los dictados del visitador eclesiástico y apelar a la Audiencia parecía ser la estratagema de todos aquellos que se lucraban sin pudor con el ejercicio de su mayordomía. Que ese sacristán acatase la orden del visitador bajo la amenaza de perder la sacristía en la parroquia delataba también cuánto podía llegar a significar un oficio menor como aquel, un asidero en un mundo de frágiles superviviencias.

Comportamientos similares que expresaban egoismo y codicia encontró el visitador en Beas donde los mayordomos de los hospitales, cuyas malas prácticas podrían ser un ejemplo de formación originaria de capital a partir de la especulación con la escasez, tenían a juicio de Frías y de anteriores visitadores

particular granjería en el trigo que tienen de renta los hospitales cargándose de ello a dinero los años caros a la tasa y vendiéndolo por mucho más. Y aunque el doctor Jerónimo Pacheco mandó que hiciesen graneros en que guardarlos y que en ańos semejantes se vendiese a los pobres de la villa a la tassa que era hacerles harta limosna no cumplieron ni esto ni otras cosas que mandó y lo mismo han hecho en las que yo dexé ordenados ${ }^{40}$. 
Tales actitudes remiten a la imagen de los pastores que no guardan el rebaño sino que lo roban, tan presente en la literatura y especialmente en la espańola del siglo XVII. Sin ir más lejos, a pesar de que el visitador reconocía no haber visitado los hospitales de Niebla, sus noticias no eran mejores, pues

dícenme que hay hospitales ricos y mucha desorden y comúnmente se dice entre los cofrades que a quien quieren aprovechar y dar de comer le hazen mayordomo de un hospital por lo que se le pega (sic) del manejar la hazienda de los pobres.

Y no estaría descaminada esta opinión común en la capital del señorío porque pocos años antes, en 1583, con ocasión de una visita que mandó hacer el VII duque de Medina Sidonia por los lugares de su Condado, se observaron por parte de los visitadores, el padre maestro fray Agustín de Salcedo y un letrado de su consejo, el licenciado Agustín Hernández, los síntomas del mal que los informadores de Frías corroborarían después ${ }^{41}$ :

Asimismo suplican a V.E. pida al arçobispo que se tenga cuenta con los grandes alcances que a priostes y mayordomos de los hospitales de Niebla se han hecho y nunca se han cobrado ni pagado. Y pues desto ni ricos y réditos se pueden favorescer, favoresca a los pobres, no los coman los que no lo son. Y habiendo buenos mayordomos y buena cuenta se remedia todo.

Tenía pruebas suficientes el arcediano hispalense para concluir que los mayordomos constituían un grupo profesional que gobernaba los hospitales sin obstáculo alguno que impidiese su enriquecimiento, por relativo que éste fuese, o que manejasen con el beneplácito implícito de las cofradías los bienes que estas les entregasen para su gestión sin más control que el que ejercieran los propios cofrades sobre él. Sabiéndose conocedores en un mundo de ignorantes como aquel de un oficio para el que se presumía cierta pericia contable y mercantil, representaron en el seno de sus comunidades rurales un papel destacado en la construcción de redes clientelares de indudable influencia en la vida social y económica rural. Cuando el visitador señorial apuntaba la necesidad de buenos mayordomos para los hospitales no se estaba refiriendo a la capacidad para el ejercicio del cargo sino al perfil moral de aquellos que lo ocupaban. Su optimismo sugería una solución moral a un problema inmoral, aunque desconocer la realidad de las cosas es la raíz de todos los errores.

Frías sabía muy bien, por su experiencia en Sanlúcar, que nada se podía hacer sino restaurar, al menos, el principio de autoridad perdido. No obstante, su paso 
por Huelva sería también decepcionante pues allí serían los clérigos que administraban un hospital para curación de enfermos quienes se opusieron a que los legos les sustituyeran en el gobierno de la institución, como había propuesto un visitador anterior a Frías. Que se habían salido con la suya era evidente pues no lo habían cumplido e incluso no aceptaban la intervención del visitador negándole los derechos de la visita a que estaban obligados.

El párrafo final de su memoria resume muy bien su decepción, su opinión certera acerca del remedio a los males, cuyos causantes se desenmascaran, y su categórica consideración sobre la solución, es decir, restaurar el principio de autoridad de los visitadores sobre la base de una delegación real en sus manos de competencias disciplinares y no de una mera representación institucional del poder.

Conforme a esto y a otras cosas que por evitar prolixidad no refiero, sería necesarísimo poner remedio eficaz para que los mayordomos y administradores de los hospitales diesen en las visitas la quenta que es razón y no la que ellos quieren, pues lo primero sería visitar con effeto y lo demás no sirve de nada.

El doctor Pedro de Frías

Sin embargo, a pesar del juicio certero de Frías, la reducción de los hospitales era una cuestión independiente de su capacidad de maniobra y tenía que ver, sobre todo, con la situación económica de cada hospital en el momento mismo de la reducción, con su pobreza o con su riqueza patrimonial, resultado o no de la pésima gestión denunciada. La pregunta que corresponde ahora es saber si la política reductora fue un éxito o un fracaso, si produjo los efectos deseados o no, porque tenemos instrumentos para llegar a una conclusión. La respuesta es paradójica: en el caso de la Palma, donde no se llevó a cabo la reducción, los hospitales sobrevivieron hasta la reducción hospitalaria liberal de mediados del siglo XIX y lo hicieron sin pasar agobios de tesorería, aumentando sus ingresos en los siglos XVII y XVIII, diversificando sus gastos salariales y funcionales, incrementando su asistencia social y sanitaria, como ponen de manifiesto los libros de cuenta conservados ${ }^{42}$. Así pues, la reducción iniciada en tiempos de Felipe II fracasó si analizamos la historia de los hospitales de La Palma hasta el siglo XIX, pero eso no quiere decir que lo sucedido en esa villa sea extrapolable a otras. Porque, en cambio, creo que la reducción que se llevó a cabo en Niebla fue un éxito rotundo pues desembocó en la concentración en un solo hospital de las rentas de los demás, amplió su oferta hospitalaria, redujo gastos y aumentó ingresos y sirvió muy eficazmente a los fines que perseguía la política real. 
Más allá del patrimonio y los ingresos que cada hospital tuviese, la reducción tuvo que ver fundamentalmente con la eficacia de la gestión, esto es, con la mayor o menor capacidad asistencial de cada hospital. En La Palma, los tres hospitales que sobrevivieron a la reducción del siglo XVI desarrollaron e incrementaron una labor asistencial y educativa de un enorme valor social hasta mediados del siglo XIX. Por su parte, en Niebla, cuyos hospitales no pudieron resistir la fuerza de la política reductora, se mantuvo la hospitalidad, una hospitalidad eficaz, gracias a la reducción. 